http:// bjas.bu.edu.eg

\title{
Comparative Evaluation of an Inactivated Trivalent FMD Vaccine Adjuvant with either Montanide Oil ISA 206 or 201 in Sheep \\ G.F.El-Bagoury $^{1}$, A.S.El-Habbaa ${ }^{1}$, H.A.M.Baiomy ${ }^{2}$, and H.M.El-Watany ${ }^{2}$ \\ ${ }^{1}$ Virology Dept ., Faculty of Veterinary Medicine, Benha Univ., Benha, Egypt \\ ${ }^{2}$ Foot and Mouth Disease Vaccine Research Dept.,Veterinary Serum and Vaccine Research Institute, Abbasia, Cairo. \\ E-Mail: AYMAN.EL-HBBAK@fvtm.bu.edu.eg
}

\begin{abstract}
The extraction of cobalt from chloride medium using two organophorous extractants: bis $(2,4,4-$ trimethylpentyl) phosphinic acid (Cyanex 272) and di-(2-ethyl-hexyl) phosphoric acid (D2EHPA) was studied. The important parameters governing the extraction of cobalt have been studied. Foot and mouth disease (FMD) is a contagious disease of domesticated and wild cloven-hoofed animals with serious losses of production and prenatal mortalities. Vaccination is widely used to control FMD in Egypt. This study aimed for comparative evaluation of an inactivated trivalent FMD vaccine with either using montanide oil ISA 206 or 201 adjuvants that were applied in sheep. The prepared vaccines proved sterile and safe. Neutralizing antibodies against serotypes $\mathrm{O}, \mathrm{A}$ and SAT2 FMD virus reached the protective titers at the $3^{\text {rd }}$ and $2^{\text {nd }}$ week post vaccination (wPV) for sheep vaccinated with FMD vaccine based on ISA 206 and 201 oil adjuvants, respectively. These antibody titers persisted in protective level till 32 wPV against serotypes A and SAT2 FMD virus and till 36 wPV against serotype $\mathrm{O}$ for sheep vaccinated with FMD vaccine based on ISA 206 oil adjuvant. Neutralizing antibody titers against serotypes O, A and SAT2 FMD virus persisted in protective level for $40 \mathrm{wPV}$ for sheep vaccinated with FMD vaccine based on ISA 201 oil adjuvant. These results were confirmed using ELISA. Evaluation of FMD virus-specific cell-mediated immunity using XTT assay showed high lymphocyte proliferation expressed by optical density from the $3^{\text {rd }}$ day post vaccination $(\mathrm{dPV})$, increased to reach a maximum value $2^{\text {nd }}$ wPV and persisted in a high level till $9^{\text {th }}$ wPV for FMD virus types O, A and SAT2 inducers for both sheep groups vaccinated with inactivated trivalent FMD vaccine either using montanide oil ISA 206 or 201 adjuvant. Finally, it was concluded that the inactivated trivalent FMD vaccine with ISA-201 oil adjuvant was superior than the vaccine with ISA-206 adjuvant in giving earlier and longer duration immune response in vaccinated sheep.
\end{abstract}

Keywords: FMD vaccine, Sheep, SNT, ELISA, XTT assay.

\section{Introduction}

Foot-and-mouth disease (FMD) is an acute, febrile, and highly contagious disease affecting domestic and wild cloven-hoofed animals [14].

The economic impact of the disease includes losses of production, and prenatal mortalities [24]. FMD virus belongs to the genus Aphthovirus, family Picornaviridae.

It occurs in seven distinct serotypes (A, C, O, Asia 1, and SAT 1-3) [21]. FMD is widely distributed throughout South America, Africa, the Middle East, and Asia. In Egypt, many outbreaks of FMD have been occurring with serotypes $\mathrm{O}$, A and SAT2 [23].

Although, control of FMD is based on largescale vaccinations with whole-virus inactivated vaccines in endemic countries, diversity of FMD virus in nature (seven serotypes and 65 subtypes) causes difficulties in FMD eradication [18]. Montanide oil adjuvants appear to be promising candidates for the new generation of FMD vaccines in cattle [9], [15].

This study aimed for comparative evaluation of inactivated trivalent FMD vaccines using montanide ISA 206 and 201 in sheep.

\section{Materials and methods}

2.1 Foot and mouth disease (FMD) virus strains A tissue culture adapted FMD virus strains including $\mathrm{O}$ pan asia, A/Iran 05 and SAT2/EGY/2012 of cattle origin, were typed and subtyped at the FMD Department, Veterinary Serum and Vaccine Research Institute (VSVRI), Abassia, Cairo and confirmed by the World Reference Laboratories, Pirbright, United Kingdom. The viral strains were stored at $-70{ }^{\circ} \mathrm{C}$ and were used as seed virus for preparation of the vaccines and in Complement Fixation Test (CFT), Serum Neutralization Test (SNT), Enzyme Linked Immuno-Sorbent Assay (ELISA) and XTT assay.

\subsection{Baby hamster kidney cell line (BHK21 clone} 13)

It was supplied by the Animal Research Institute, Pirbright, UK. It was propagated at FMD Department, VSVRI, Abbasia, Cairo, Egypt by using of minimum Essential Medium (MEM) with Eagle's salts and with $10 \%$ new born calf serum [20]. These cells were used for virus propagation and titration and for SNT. 
2.3 Experimental Sheep

A total number of 29 adult susceptible sheep local breed of about $35-50 \mathrm{~kg}$ body weight, clinically healthy and were not vaccinated against FMD. The sheep were tested to be free from antibodies against FMD viruses before the experimental work using SNT and were used for evaluation of the prepared inactivated FMD vaccines with Montanide ISA206 and ISA201 adjuvants.

\subsection{Vaccines formulation}

Each FMD virus strain was inoculated onto a monolayer BHK-21 cell line that harvested at over $70 \%$ cytopathic effect after $36 \mathrm{~h}$, and then it was purified by centrifugation at $3000 \mathrm{rpm}$ for 20 minutes to remove cell debris [19]. Titer of the tissue culture adapted virus was estimated on BHK21 cell line [25] and its antigenicity was titrated using Complement Fixation Test (CFT), [27]. The seed FMD virus strains had a titer of $10^{8} \mathrm{TCID} 50 / \mathrm{ml}$ and 32 using infectivity titration and CFT, respectively for each FMD virus strain. They were inactivated by a combination of Binary Ethyleneimine (BEI) $1 \mathrm{mM}$ and $0.04 \%$ formaldehyde [5] and the vaccines were formulated where the oil phase (either consisted of Montanide ISA 206 or ISA 201) mixed as equal parts of an aqueous and oil phase weight/ weight and mixed to make water-in-oil-in-water suspension [3].

\subsection{Quality control of the prepared vaccines}

Sterility and safety were evaluated for the prepared inactivated trivalent FMD vaccines [8].

\subsection{Experimental design}

Sheep were used for evaluation of the prepared inactivated trivalent FMD vaccines as follow:

Group (1): Ten sheep were vaccinated with 1.5 $\mathrm{ml} /$ animal (S/C) of the prepared inactivated trivalent FMD vaccine based on Montanide oil ISA 206 adjuvant as one dose.

Group (2): Ten sheep were vaccinated with 1.5 $\mathrm{ml} /$ animal (S/C) of the prepared inactivated trivalent FMD vaccine based on Montanide oil ISA 201 adjuvant as one dose.

Group (3): Five sheep were kept as control without vaccination.

Group (4): Two sheep were used in safety test of the of the prepared inactivated trivalent FMD vaccine based on Montanide oil ISA 206 adjuvant.
Group (5): Two sheep were used in safety test of the prepared inactivated trivalent FMD vaccine based on Montanide oil ISA 201 adjuvant

Blood samples collected on heparin as anticoagulant for evaluation of cell- mediated immune response before and after vaccination $\left(3^{\text {rd }}\right.$, $7^{\text {th }}, 10^{\text {th }}$ days and 2 weeks post vaccination then weekly till $9^{\text {th }}$ week post vaccination. Serum samples from animals in groups (1), (2) and (3) were collected before vaccination and weekly after vaccination for 40 weeks to measure the efficacy and duration of immunity in vaccinated sheep using SNT and ELISA.

\subsection{Cell proliferation assay XTT}

Growth and proliferation of lymphocyte was determined using Cell Proliferation Kit II (XTT) Colorimetric assay (XTT based) for the nonradioactive quantification of cell proliferation and viability according to the manufacturer instruction, Cat. No. 11465015001 (Roche Applied Science, Mannheim, Germany).

\subsection{Serum neutralization test (SNT)}

SNT was performed using the micro-technique to detect serum neutralizing antibodies against FMD virus serotypes $\mathrm{O}, \mathrm{A}$ and SAT2. The antibody titer was estimated as the reciprocal of the final serum dilution which neutralized and inhibited the CPE of $100 \mathrm{TCID}_{50}$ of FMD virus serotypes O, A and SAT2 [12].

\subsubsection{Enzyme linked immunosorbent assay (ELISA)}

FMD virus serotypes $\mathrm{O}$, A and SAT2 antigens were prepared from infected BHK -21 cells and concentrated by PEG (6000), [29], then used in ELISA to estimate the specific antibodies of different serotypes of FMD virus [28].

\section{Results}

\subsection{Sterility and safety of the vaccine}

The prepared vaccines were free from aerobic and anaerobic bacteria and fungi. They were also safe and gave satisfactory results indicated by absence of cytopathic effect on tissue culture, and absence of local and systemic reactions on inoculated sheep with no rise in body temperature.

\subsection{Humeral immune response}

Regarding sheep vaccinated with inactivated trivalent FMD vaccine based on ISA 206, neutralizing antibodies against serotypes $\mathrm{O}, \mathrm{A}$ and 
SAT2 FMD virus reached the protective titers at the $3^{\text {rd }}$ week post vaccination (wPV), persisted in protective level against serotypes A and SAT2 FMD virus till 32 wPV and neutralizing antibody titers against serotype $O$ FMD virus persisted in protective level for $36 \mathrm{wPV}$.

For sheep vaccinated with inactivated trivalent FMD vaccine based on ISA 201, neutralizing antibodies against serotypes $\mathrm{O}, \mathrm{A}$ and SAT2 FMD virus reached the protective titers at the $2^{\text {nd }} \mathrm{wPV}$, persisted in protective level against serotypes $\mathrm{O}$, A and SAT2 FMD virus till $40 \mathrm{wPV}$. These results were compared with that of control non-vaccinated sheep groups were shown in table (1).

Humeral immune response evaluated using ELISA showed that antibody titers for FMD virus serotypes O, A and SAT2 started to increase from the first WPV and persisted in positive level until $40^{\text {th }}$ wPV for both sheep groups vaccinated with inactivated trivalent FMD vaccine either using montanide oil ISA 206 or 201 adjuvant. These results compared to the control groups were shown in table (2).

\subsection{Cell mediated immune response}

Evaluation of FMD virus-specific cell-mediated immunity using XTT assay showed high lymphocyte proliferation expressed by optical density from the $3^{\text {rd }}$ day post vaccination (dPV), increased to reach a maximum value $2^{\text {nd }}$ wPV and persisted in a high level till $9^{\text {th }}$ wPV for FMD virus types O, A and SAT2 inducers for both sheep groups vaccinated with inactivated trivalent FMD vaccine either using montanide oil ISA 206 or 201 adjuvant. These results were compared with that of control non-vaccinated sheep group that had no lymphocyte proliferation against FMDV as shown in table (3).

\section{Discussion}

Titration of FMD virus strains used as the seed for vaccines preparation revealed that FMD virus serotypes (O pan Asia, A/Iran 05 and SAT2/EGY/2012) were of high infectivity and antigenicity titers (infectivity titer is $10^{8}$ TCID50/ml for each serotype and complement fixation titer is 32 for the three virus serotypes). These tissue culture adapted serotypes of FMD virus were used as the seed viruses for the prepared vaccines were inactivated then inoculated on BHK cell line without appearance of any CPE after 72 hours of incubation at $37^{\circ} \mathrm{C}$ indicating no viable viral residues. This step agrees with the study stated that there are three important factors essential to produce FMD vaccine including viral propagation for large scale production, virus inactivation without residual infectivity remains and addition of a non-toxic adjuvant to enhance the immune response to a satisfactory level [10].

Two batches of inactivated trivalent FMD vaccine were formulated using ISA 206 and 201 as adjuvants from FMD virus serotypes $(\mathrm{O} /$ pan Asia, A/Iran 05, SAT2/EGY/2012) after their purification and concentration and inactivation (each dose of vaccine contains not less than $10^{8} \mathrm{TCID}_{50} /$ dose for each FMD virus strain), [3]. Each prepared vaccine was tested for its sterility and purity from any bacterial or fungal contaminants on Tryptose phosphate broth, Thioglcolate broth, Sabouraud's agar and mycoplasma medium [8]. It was noticed that all vaccinated animals did not show any FMD clinical signs post vaccination indicating safety of the prepared inactivated trivalent FMD vaccines based on ISA 206 and ISA 201 adjuvants. These prepared inactivated trivalent FMD vaccines based on ISA 206 and ISA 201 adjuvants were evaluated in local breed adult susceptible sheep, clinically healthy and free from antibodies against FMD virus serotypes $\mathrm{O}_{1} / 3 / 93, \mathrm{~A} / \mathrm{Egypt} / 2006$ and SAT 2/EGY/2012 as proved by using SNT [12].

Evaluation of humeral immune response of sheep vaccinated with inactivated trivalent FMD vaccine based on ISA 206 adjuvant showed that the protective neutralizing antibody titers (1.5) against serotypes O, A and SAT2 FMD virus were reached the protective titers at the $3^{\text {rd }}$ week post vaccination (wPV) and persisted till 32 wPV against serotypes A and SAT2 FMD virus and till 36 wPV against serotype O FMD virus. For sheep vaccinated with inactivated trivalent FMD vaccine adjuvant on montanide ISA 201 protective neutralizing antibody titer for FMD virus serotypes O, A and SAT2 started from the $2^{\text {nd }} \mathrm{wPV}$ and persisted in protective level until $40^{\text {th }} w P V$. These results compared to the control groups were shown in table (1) and agreed with findings of the studies proved good humoral immune response of cattle to oil adjuvant inactivated FMD vaccines evaluated using SNT [1], [6], [16].

Humeral immune response evaluated using ELISA showed that antibody titers for FMD virus serotypes O, A and SAT2 started to increase from 
the first wPV and persisted in positive level until $40^{\text {th }}$ wPV for both sheep groups vaccinated with inactivated trivalent FMD vaccine either using montanide oil ISA 206 or 201 adjuvant. These results compared to the control groups were shown in table (2). These results confirmed the results of SNT. These findings agree with the studies proved good humoral immune response of cattle to oil adjuvant inactivated FMD vaccines evaluated using ELISA [2], [7], [13], [24], [26]. Evaluation of FMD virus-specific cell-mediated immunity using XTT assay showed high lymphocyte proliferation expressed by optical density from the $3^{\text {rd }}$ day post vaccination (dPV), increased to reach a maximum value $2^{\text {nd }}$ wPV and persisted in a high level till $9^{\text {th }}$ wPV for FMD virus types O, A and SAT2 inducers for both sheep groups vaccinated with inactivated trivalent FMD vaccine either using montanide oil ISA 206 or 201 adjuvant. These results were compared with that of control non-vaccinated sheep group that had no lymphocyte proliferation against FMDV as shown in table (3). These results came in agreement with the study found highest delta optical density level for ISA 206 on 14 and 21 days post vaccination (DPV), [17]. Also, these results agreed with the study stated that an adjuvant acts in one or more of five ways, based on current knowledge; namely, immune-modulation, presentation, induction of $\mathrm{CD} 8+$ cytotoxic $\mathrm{T}$ lymphocyte (CTL) responses, targeting, and depot generation. Addition to that adjuvant plays an important role in production of different lymphokines such as various interleukins and INFgamma[4],[11].

Table (1) mean neutralizing antibody titers against FMD virus in sera of vaccinated sheep with inactivated trivalent FMD vaccine based on ISA 206 and ISA 201 adjuvants using SNT.

\begin{tabular}{ccccccccccc}
\hline \multirow{2}{*}{$\begin{array}{c}\text { Weeks } \\
\text { Post }\end{array}$} & \multicolumn{7}{c}{ Mean log $_{10}$ neutralizing antibody titers } \\
\cline { 2 - 9 } Vacc. & ISA206 & ISA201 & Control & ISA206 & ISA201 & Control & ISA206 & ISA201 & Control \\
\hline 0 & 0.24 & 0.33 & 0.30 & 0.22 & 0.34 & 0.32 & 0.28 & 0.28 & 0.32 \\
1 & 0.82 & 1.30 & 0.32 & 0.82 & 1.27 & 0.32 & 0.85 & 1.32 & 0.31 \\
2 & 1.21 & 1.73 & 0.36 & 1.30 & 1.73 & 0.34 & 1.32 & 1.65 & 0.33 \\
3 & 1.67 & 1.98 & 0.35 & 1.69 & 1.97 & 0.36 & 1.65 & 2.05 & 0.34 \\
4 & 1.94 & 2.30 & 0.35 & 1.92 & 2.27 & 0.35 & 1.84 & 2.32 & 0.34 \\
6 & 2.29 & 2.60 & 0.35 & 2.20 & 2.56 & 0.35 & 2.05 & 2.60 & 0.35 \\
8 & 2.50 & 2.80 & 0.39 & 2.44 & 2.78 & 0.39 & 2.32 & 2.81 & 0.36 \\
10 & 2.70 & 2.90 & 0.39 & 2.68 & 2.89 & 0.39 & 2.60 & 2.92 & 0.39 \\
12 & 2.66 & 3.10 & 0.35 & 2.72 & 3.09 & 0.35 & 2.53 & 3.11 & 0.36 \\
14 & 2.56 & 2.85 & 0.39 & 2.50 & 2.99 & 0.39 & 2.39 & 2.98 & 0.36 \\
16 & 2.37 & 2.69 & 0.32 & 2.38 & 2.81 & 0.32 & 2.26 & 2.83 & 0.35 \\
18 & 2.26 & 2.58 & 0.30 & 2.21 & 2.64 & 0.30 & 2.04 & 2.62 & 0.30 \\
20 & 2.12 & 2.38 & 0.32 & 2.08 & 2.45 & 0.32 & 1.90 & 2.46 & 0.30 \\
24 & 1.97 & 2.24 & 0.30 & 1.90 & 2.29 & 0.30 & 1.82 & 2.32 & 0.30 \\
28 & 1.83 & 2.05 & 0.31 & 1.65 & 2.09 & 0.31 & 1.67 & 2.14 & 0.30 \\
32 & 1.69 & 1.85 & 0.30 & 1.48 & 1.88 & 0.30 & 1.52 & 1.90 & 0.30 \\
36 & 1.49 & 1.67 & 0.30 & 1.25 & 1.69 & 0.30 & 1.19 & 1.67 & 0.30 \\
40 & 1.16 & 1.45 & 0.30 & 1.03 & 1.48 & 0.30 & 0.85 & 1.52 & 0.30 \\
\hline
\end{tabular}

Protective serum neutralizing antibody titer $=1.5 \log 10$ according to OIE (2012)

Values calculated as geometric mean. 
Table (2) mean serum antibody titers against FMD virus in sera of sheep vaccinated with inactivated trivalent FMDV vaccine adjuvant with montanide oil ISA 206 and ISA 201 using ELISA.

\begin{tabular}{cccccccccc}
\hline \multirow{2}{*}{$\begin{array}{c}\text { Weeks } \\
\text { Post }\end{array}$} & \multicolumn{7}{c}{ Mean $\log _{\mathbf{1 0}}$ Serum antibody titers using ELISA } \\
\cline { 2 - 9 } Vacc. & ISA206 & ISA201 & Control & ISA206 & ISA201 & Control & ISA206 & ISA201 & Control \\
\cline { 2 - 9 }$y$ & 0.53 & 0.62 & 0.41 & 0.60 & 0.61 & 0.41 & 0.59 & 0.59 & 0.41 \\
1 & 1.11 & 1.69 & 0.41 & 1.17 & 1.70 & 0.41 & 1.17 & 1.75 & 0.41 \\
2 & 1.55 & 2.13 & 0.45 & 1.72 & 2.08 & 0.45 & 1.70 & 2.08 & 0.45 \\
3 & 2.00 & 2.46 & 0.45 & 1.99 & 2.28 & 0.45 & 1.98 & 2.47 & 0.45 \\
4 & 2.26 & 2.67 & 0.42 & 2.24 & 2.62 & 0.42 & 2.19 & 2.76 & 0.42 \\
6 & 2.58 & 2.94 & 0.45 & 2.49 & 2.88 & 0.45 & 2.40 & 2.94 & 0.45 \\
8 & 2.84 & 3.10 & 0.50 & 2.69 & 3.02 & 0.50 & 2.70 & 3.12 & 0.50 \\
10 & 2.90 & 3.23 & 0.51 & 3.02 & 3.17 & 0.51 & 2.97 & 3.17 & 0.51 \\
12 & 3.16 & 3.37 & 0.46 & 3.04 & 3.36 & 0.46 & 2.91 & 3.42 & 0.46 \\
14 & 2.83 & 3.18 & 0.49 & 2.84 & 3.28 & 0.49 & 2.79 & 3.09 & 0.49 \\
16 & 2.66 & 3.02 & 0.45 & 2.75 & 3.13 & 0.45 & 2.62 & 3.17 & 0.45 \\
18 & 2.55 & 2.90 & 0.40 & 2.60 & 2.98 & 0.40 & 2.45 & 3.02 & 0.40 \\
20 & 2.46 & 2.73 & 0.45 & 2.42 & 2.84 & 0.45 & 2.26 & 2.88 & 0.45 \\
24 & 2.28 & 2.55 & 0.41 & 2.28 & 2.66 & 0.41 & 2.17 & 2.72 & 0.41 \\
28 & 2.13 & 2.40 & 0.41 & 2.03 & 2.63 & 0.41 & 1.99 & 2.53 & 0.41 \\
32 & 1.96 & 2.21 & 0.41 & 1.89 & 2.25 & 0.41 & 1.84 & 2.37 & 0.41 \\
36 & 1.75 & 2.04 & 0.41 & 1.65 & 2.08 & 0.41 & 1.54 & 2.06 & 0.41 \\
40 & 1.37 & 1.85 & 0.40 & 1.35 & 1.90 & 0.40 & 1.08 & 1.92 & 0.40 \\
\hline
\end{tabular}

Values calculated as geometric mean.

Table (3) mean delta optical density of lymphocyte proliferation of sheep vaccinated with inactivated trivalent FMDV vaccine adjuvant with montanide oil ISA 206 and ISA 201 using XTT assay:

\begin{tabular}{ccccccccccc}
\hline \multirow{2}{*}{$\begin{array}{c}\text { Time } \\
\text { Post } \\
\text { vacc. }\end{array}$} & \multicolumn{4}{c}{ Mean delta optical density of the lymphocyte proliferation against FMD virus } \\
\cline { 2 - 10 } & \multicolumn{3}{c}{ Serotype O } & \multicolumn{4}{c}{ Serotype A } & \multicolumn{3}{c}{ Serotype SAT2 } \\
\hline 0 & 0.046 & 0.048 & 0.052 & 0.046 & 0.050 & 0.052 & 0.043 & 0.050 & 0.052 \\
3dpv & 0.490 & 0.517 & 0.051 & 0.451 & 0.504 & 0.051 & 0.397 & 0.517 & 0.051 \\
7dpv & 0.476 & 0.863 & 0.052 & 0.475 & 0.832 & 0.052 & 0.475 & 0.870 & 0.052 \\
10dpv & 0.775 & 1.691 & 0.052 & 0.760 & 1.460 & 0.052 & 0.782 & 1.585 & 0.052 \\
2wpv & 1.115 & 2.018 & 0.052 & 1.103 & 1.958 & 0.052 & 1.097 & 1.999 & 0.052 \\
3wpv & 0.876 & 1.658 & 0.052 & 0.918 & 1.617 & 0.052 & 0.912 & 1.688 & 0.052 \\
4wpv & 0.778 & 1.453 & 0.052 & 0.756 & 1.380 & 0.052 & 0.784 & 1.477 & 0.052 \\
5wpv & 0.677 & 0.940 & 0.052 & 0.662 & 1.006 & 0.052 & 0.730 & 1.023 & 0.052 \\
6wpv & 0.633 & 0.828 & 0.052 & 0.626 & 0.894 & 0.052 & 0.630 & 0.889 & 0.052 \\
7wpv & 0.492 & 0.823 & 0.052 & 0.457 & 0.816 & 0.052 & 0.425 & 0.828 & 0.052 \\
8wpv & 0.467 & 0.767 & 0.052 & 0.421 & 0.713 & 0.052 & 0.710 & 0.762 & 0.052 \\
9 wpv & 0.046 & 0.048 & 0.052 & 0.046 & 0.050 & 0.052 & 0.043 & 0.050 & 0.052 \\
\hline
\end{tabular}

Values calculated as geometric mean. 


\section{Conclusion}

Both vaccines induced good humoral and cellular immune responses in sheep, the inactivated trivalent FMD vaccine with ISA-201 oil adjuvant was superior than the vaccine with ISA-206 adjuvant in giving earlier and longer duration immune response in vaccinated sheep.

\section{References}

[1]A.O.Abd El-Rahman, A.M.H.Azab, A.M.Aggour, F.A.A.Moussa, M.Abo ElYazeid, Studies on cellular and humeral immune response in cattle against FMD bivalent vaccine. J. Egypt, Assuit Veterinary Medicine, vol. 67(2), pp. 265-272, 2007.

[2] A.L.Barnard, A.Arriens, S.Cox, P.Barnett, B.Kristensen, A.Summerfi, K.C.McCullough, Immune response characteristics following emergency vaccination of Pigs against FMD, Vaccine, vol. 23(8), pp. 1037-1047, 2005.

[3] P.Barnett, L.Pullen, L.Williams, T.R.Doel, Assessment of Montanide ISA 25 and ISA 206, two commercially available oil adjuvant, Vaccine, vol. 14 (13), pp. 1187-1198, 1996.

[4] P.V.Barnett, P.Keel, S.Reid, R.M.Armstrong, R.J.Statham, C.Voyce, N.Aggarwal, , S.J.Cox, Evidence that high potency foot and mouth disease vaccine inhibits local virus replication and prevents the 'carrier' state in sheep, Vaccine, vol. 22, pp.1221-1232, 2004.

[5] S.J.Barteling, N.I.Cassim, Very fast (and safe) inactivation of FMD virus and enteroiruses by a combination of binary ethylenimine and formaldehyde. Schudel, A., Lombard, M. editors. Control of Infections Animal Disease by Vaccination. Vol. 119. Kager, Basel. Pp. 449-455, 2004.

[6] S.J.Barteling, K.J.Vreeswij, Development in foot and mouth disease vaccine, Vaccine, vol. 9(2), pp. 75-88, 1991.

[7] J.Bayry, K.Prabhudas, S.Gopalakrishna, P.K.Patil, C.Ramakrishna, L.D.Mishra, V.V.S.Suryanarayana, Protective immune response to $16 \mathrm{kDa}$ immunoreactive recombinant protein encoding the $\mathrm{C}$-terminal VP1 portion of Foot and Mouth Disease Virus type Asia I, Microbiol. Immunol., vol. 43, pp. 768-771, 1999.

[8] Code of Federal Regulation of USA (CFR), Published by the office of the federal register national archives and Record administration, Animal and animal products 9\1986, 1986.
[9] P.Dar, R.Kalaivanan, N.Sied, B.Mamo, S.Kishore, V. V. Suryanarayana, G.Kondabattula, Montanide ISA $^{\text {TM }} 201$ adjuvanted FMD vaccine induces improved immune responses and protection in cattle, Vaccine, vol. 31(33), pp. 3327-3332, 2013.

[10] W.Deghaidy, A.Daoud, A.El-Molla, Immune response of sheep to foot and mouth disease vaccines containing different adjuvants, Small Ruminant Research, vol. 45, pp.185-192, 2002.

[11] M.Ebeid, F.K.Hamouda, M.Farag, S.E.Mahdy, Detection of sub-clinical cases in emergency vaccinated animals after challenged with foot and mouth disease virus, Benha Veterinary Medical Journal, special issue [ii], 4th Sci. Conf., Al-Kasr 25-28 May, 2011, Fac. Vet. Med., Benha University, Egypt, 2011.

[12] M.E.V.Ferreira, Prubade microneutralization poraestudies de anticueropos de la fibre aftosa, 13th Centropanamericano Fibre aftosa, vol. 21/22, pp.17-24, 1976.

[13] J.H.Graves, K.M.Cowan, R.Trautman, Immunochemical studies of FMDV characterization of RNA free virus like particles, Virology, vol. 34, pp. 269-274, 1968.

[14] M.J.Grubman, B.Baxt, Foot and mouth disease, Clin. Microbiol., vol. 17(2), pp. 46593, 2004.

[15] R.B.Gurung, A.C.Purdie, R.J.Whittington, D.J.Begg, Cellular and humoral immune responses in sheep vaccinated with candidate antigens MAP2698c and MAP3567 from Mycobacterium avium subspecies paratuberculosis, Frontiers in Cellular and Infection Microbiology, Vol. 4, article 93, pp. $1-8,2014$

[16] H.El-Watany; M.Shawky, O.H.Roshdy, S.ElKilany, Relationship between cellular and humeral immune response in animals vaccinated with FMD vaccine, J. Egypt, Zagazig Veterinary Medicine, vol. 27(1), pp. 137-143, 1999.

[17] E.E.Ibrahim, W.M.Gamal, A.I.Hassan, S.E.Mahdy, A.Z.Hegazy, M.M.Abdel-Atty, Comparative study on the immunopotentiator effect of ISA 201, ISA 61, ISA 50, ISA 206 used in trivalent foot and mouth disease vaccine, Veterinary World, vol. 8(10), pp.1189-1198, 2015. 
[18] S.Julian, T.Jackson, C.Doel, F.Elizabeth, D.Stuart, M.H.Michiel, C.Bryan, J.Nicholas, Characterization of epitope-tagged foot-andmouth disease virus, J. Gen. Virol., vir.0.043521-o, 2012.

[19] R.A.Killington, A.Stokes, Hierolzer, Virology methods manual, Chapter 4: pp. 72-89, 1996.

[20] M.Macpherson, B.Stocker, Polyma transformation hamster cell clones, an investigation of genetic factors affecting cell competence, Virology, vol. 16, pp. 147-51, 1962.

[21] N.Lewis-Rogers, D.A.McClellan, K.A.Crandall, The evolution of foot-and-mouth disease virus: Impacts of recombination and selection. Infection, Genetics and Evolution, vol. 8, pp.786-798, 2008.

[22] OIE (Office International des Epizooties), Manual of diagnostic tests and vaccines for terrestrial animals, Chapter 2.1.5, http://www.oie.int/en/internationalstandard-setting/terrestrial-manual/accessonline. 2012.

[23] OIE, Follow-up Reports http://www.oie.int/wahis_2/temp/reports/en_f up_0000015741_20140808_120340. pdf. 2014.

[24] P.K.Patil, J.Bayry, C.Ramakrishna, B.Hugar, L.D.Misra, C.Natarajan, Immune response of goats against FMD quadrivalent vaccine: comparison of double oil emulsion and aluminum hydroxide gel vaccine in eliciting immunity, Vaccine, vol. 20, pp. 2781-2789, 2002.

[25] L.J.Reed, H.Muench, A simple method for estimating fifty percent $(50 \%)$ end points, Amer. J. Hyg., vol. 27, pp. 493-497, 1938.

[26] F.Solymon, F.Czelleng, Studies on the correct quantitative relations of antigen components in mono-, bi- and trivalent foot-and-mouth disease vaccine preparations, Dev. Biol. Stand., vol. 35, pp. 289-294, 1976.

[27] E.Traub, I.R.Manso, Uber die herstellung complement bindender merrsch-weinehon sera fur die typendiagnose bie Maul und Klauenseuche.Zbi. Bakt. Lorig., vol. 151, pp.380-381, 1944.

[28] A.Voller, D.E.Bidwell, A.Bartlett, Microplate enzyme immunoassays for the immunodiagnosis of virus infections, In Manual of Clinical Immunology, Chapter 69, edited by N. Rose and H. Friedman, pp. 506512, American Society for Microbiology, 1976.

[29] G.G.Wagner, J.L.Card, K.M.Cowan, Immunochemical studies of foot-and-mouth disease, VII. Characterization of foot-andmouth disease virus concentrated by polyethylene glycol precipitation, Arch. Ges. Virusforsch., vol. 30, pp. 343-352, 1970. 